\title{
Thermal Stability Study of Classically Immiscible Rh-Ag Alloy Nanoparticles by in situ TEM
}

\author{
Cecile S. Bonifacio ${ }^{1}$, Pranaw Kunal ${ }^{2}$, Haiqin $\mathrm{Wan}^{2}$, Simon M. Humphrey², and Judith C. Yang ${ }^{1}$ \\ 1. Department of Chemical and Petroleum Engineering, University of Pittsburgh, 4200 Fifth Ave., \\ Pittsburgh, PA \\ 2. Department of Chemistry, University of Texas at Austin, 105 East 24th Street Stop A5300, \\ Austin, TX
}

Surface structure, composition and segregation properties of bimetallic nanoalloys are crucial in determining chemical reactivity and activity $[1,2]$. RhAg nanoalloy is of interest in catalysis since $\mathrm{Rh}$, although expensive and scarce, is used in wide range of catalytic process. Alloying $\mathrm{Rh}$ with Ag seems reasonable due to Ag's abundance in nature and low cost. Unfortunately, there are no stable phase for RhAg below 2177 or $2139 \mathrm{~K}$ and $1 \mathrm{~atm}$ [3] resulting to immiscibility and it's chemical properties not well-understood. Here, stable RhAg nanoalloys were prepared using a novel microwave-assisted technique. To determine the viability of the RhAg nanoalloys for catalysis, the RhAg nanoalloy's thermal stability was investigated using electron microscopy to understand the driving forces for the nanoalloy's instabilities.

Rh-Ag mixed nanoalloys with diameter of $8 \mathrm{~nm}$ were synthesized. These nanoparticles were dispersed in hexane and drop-casted on an Aduro MEMS heating device. Using a Protochips Aduro heating holder inserted in a FEI Titan transmission electron microscope with a ChemiSTEM system, thermal annealing was performed with energy-dispersive X-ray spectra (EDS) acquired after each annealing step. The nanoparticles were annealed from $50^{\circ} \mathrm{C}$ until agglomeration of the nanoparticles was observed by $\mathrm{Z}$ contrast imaging. Subsequently, the elemental and quantitative distributions of $\mathrm{Rh}$ and $\mathrm{Ag}$ within the nanoparticle were determined from the acquired EDS maps.

Figure 1 shows the powder X-ray diffraction (PXRD) of the RhAg alloy with 1:1 molar ratio heated from $25^{\circ} \mathrm{C}$ to $350^{\circ} \mathrm{C}$ indicating a phase separation staring at $300^{\circ} \mathrm{C}$ [4]. With in situ TEM technique using similar conditions used from the PXRD, the phase segregation of $\mathrm{Ag}$ (green on the EDS maps of Figure 2) was identified to occur at the nanoalloy's surface at $350^{\circ} \mathrm{C}$.

The bulk phase diagram of RhAg indicates immiscibility for all compositions below $1400 \mathrm{~K}$ however due to size-effects at the nanoscale a metastable mixture can form. In this case, the Ag segregation was driven by the difference in the surface energies of $\mathrm{Rh}$ and $\mathrm{Ag}$ at $350^{\circ} \mathrm{C}$ where $\mathrm{Ag}$ diffusion was induced. Furthermore, catalysis experiments were conducted resulting to increased catalytic activity of Rh-rich RhAg nanoalloys[4]. Additional in situ TEM studies using Rh-rich RhAg nanoalloys to higher temperatures similar to operating temperatures in catalytic converters $\left(\sim 800^{\circ} \mathrm{C}\right)$ are underway to further investigate the thermal and structural stabilities of the RhAg nanoalloys as viable catalysts for such applications [5].

References:

[1] A.M. Molenbroek et al, Journal of Physical Chemistry B, 102 (1998) 10680

[2] G. Schmid, "In Metal Clusters in Chemistry", ed. P. Braunstein, L.A. Oro, P.R. Raithby (Wiley-VCH, Weinheim) pp. 1325

[3] R.H. Davies et al, Calphad, 26 (2002) 229

[4] S. Garcia et al, ACS Nano, 8 (2014) 11512 
[5] C.S.B and J.C.Y. acknowledge financial support by NSF DMREF (Contract No. CHE1534630) and the National Center for Electron Microscopy, at the Molecular Foundry supported by the Office of Science, Office of Basic Energy Sciences, of the U.S. Department of Energy under Contract No. DE-AC02-05CH11231. P.K., H.W. and S.M.H. were funded by NSF under contract no. CHE-1505135.

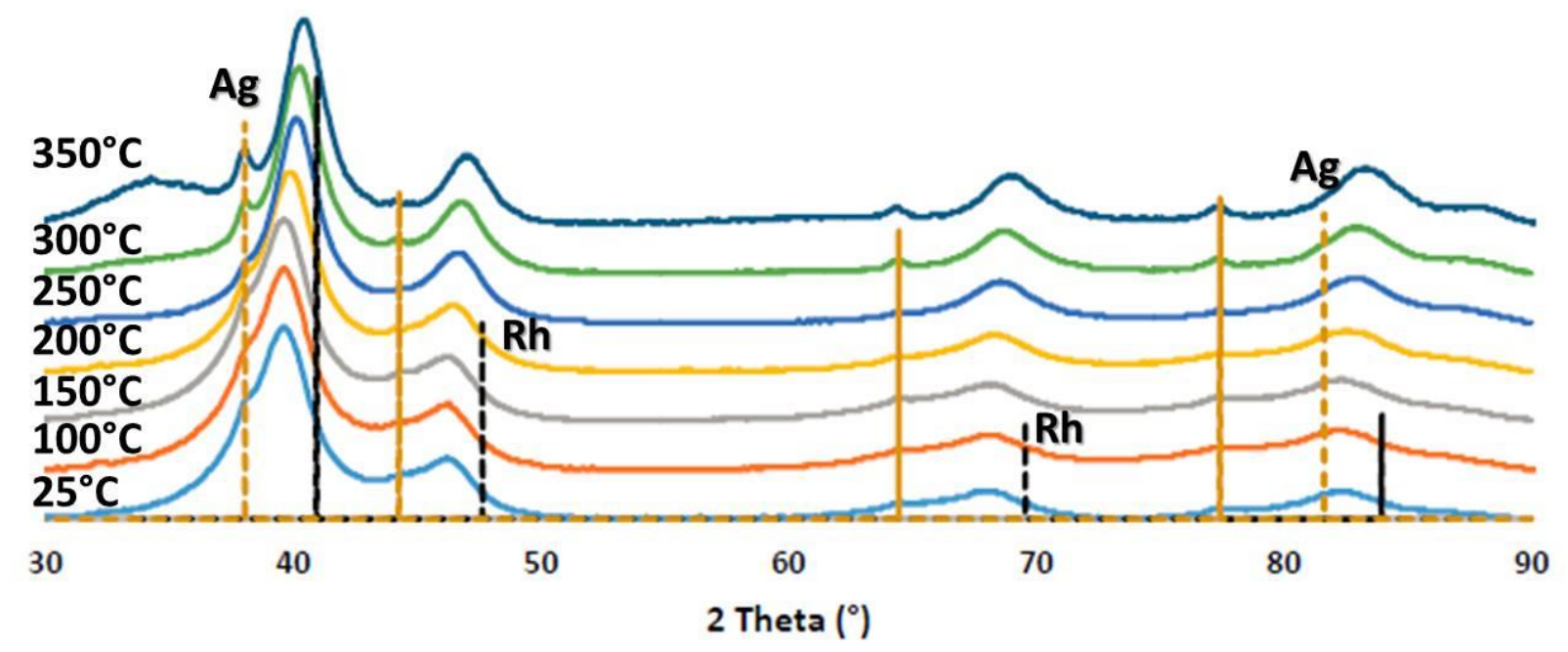

Figure 1. Powder XRD of the RhAg mixed alloy heated from $25^{\circ} \mathrm{C}$ to $350^{\circ} \mathrm{C}$. An increase in the silver (Ag) peak was observed starting at $300^{\circ} \mathrm{C}$ indicating phase segregation of the alloy[4].
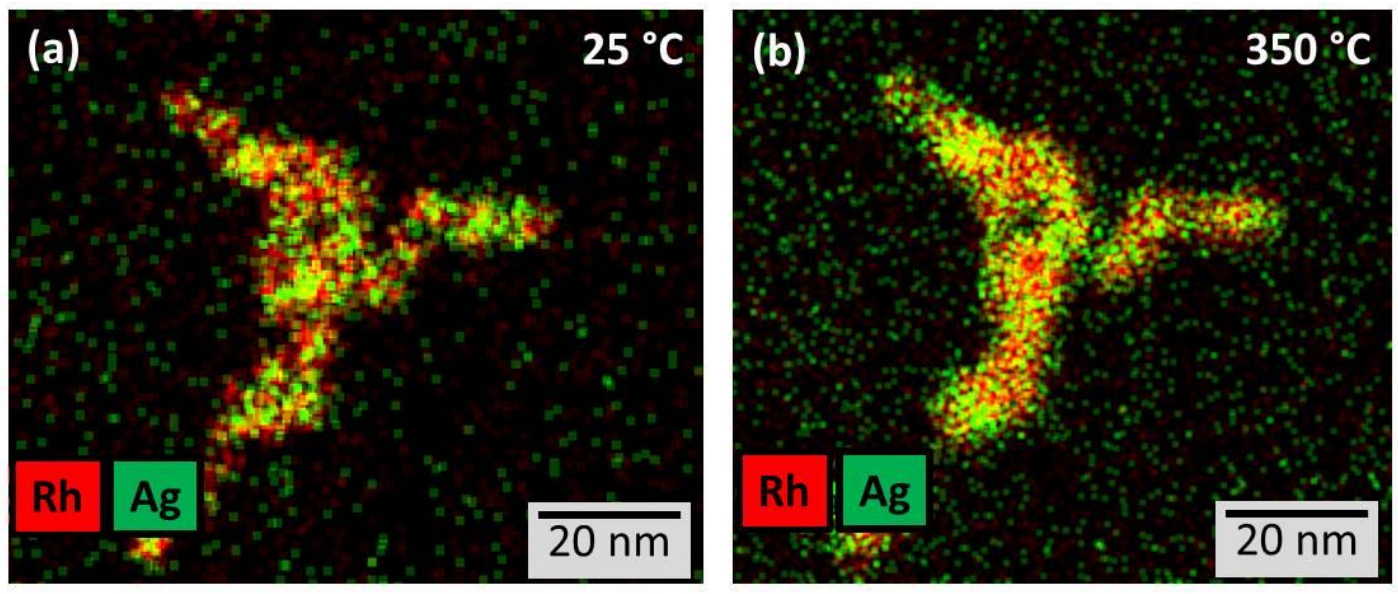

Figure 2. EDS maps of the RhAg mixed nanoalloy before annealing at $25^{\circ} \mathrm{C}$ (a) and $350^{\circ} \mathrm{C}(\mathbf{b})$. Silver segregation (green) on the surface of the nanoparticles was observed at $350^{\circ} \mathrm{C}$ correlating to PXRD results in Figure 1. 